\title{
Observations of particles at their formation sizes in Beijing, China
}

\author{
Rohan Jayaratne ${ }^{1, *}$, Buddhi Pushpawela ${ }^{1, *}$, Congrong $\mathrm{He}^{1}, \mathrm{Hui} \mathrm{Li}^{2}, \mathrm{Jian} \mathrm{Gao}^{2}$, Fahe Chai ${ }^{2}$, and Lidia Morawska ${ }^{1}$ \\ ${ }^{1}$ International Laboratory for Air Quality and Health, Queensland University of Technology, G.P.O. Box 2434, \\ Brisbane, 4001, Australia \\ ${ }^{2}$ Chinese Research Academy of Environmental Sciences, Beijing, 100012, China \\ *These authors contributed equally to this work.
}

Correspondence to: Lidia Morawska (1.morawska@qut.edu.au)

Received: 17 February 2017 - Discussion started: 1 March 2017

Revised: 12 May 2017 - Accepted: 8 June 2017 - Published: 20 July 2017

\begin{abstract}
New particle formation (NPF) has been observed in many highly polluted environments of South East Asia, including Beijing, where the extent of its contribution to intense haze events is still an open question. Estimated characteristics of NPF events, such as their starting times and formation and growth rates of particles, are more accurate when the detection range of particles extends to smaller sizes. In order to understand the very first steps of particle formation, we used a neutral cluster and air ion spectrometer (NAIS) to investigate particle characteristics at sizes exactly at which atmospheric nucleation and cluster activity occurs. Observations over a continuous 3-month period in Beijing showed 26 NPF events. These events generally coincided with periods with relatively clean air when the wind direction was from the less industrialised north. No NPF events were observed when the daily mean $\mathrm{PM}_{2.5}$ concentration exceeded $43 \mu \mathrm{g} \mathrm{m}^{-3}$, which was the upper threshold for particle formation in Beijing. The fraction of particles that are charged in the size range $2-42 \mathrm{~nm}$ was normally about $15 \%$. However, this fraction increased to $20-30 \%$ during haze events and decreased to below $10 \%$ during NPF events. With the NAIS, we very precisely determined the starting times of NPF to a greater accuracy than has been possible in Beijing before and provided a temporal distribution of NPF events with a maximum at about 08:30 LT. Particle formation rates varied between 12 and $38 \mathrm{~cm}^{-3} \mathrm{~s}^{-1}$. Particle growth rates were estimated to be in the range of $0.5-9.0 \mathrm{nmh}^{-1}$. These results are more reliable than previous studies in Beijing as the measurements were conducted for the first time at the exact sizes at which clusters form into particles and provide useful insight into the formation of haze events.
\end{abstract}

\section{Introduction}

Particles in the atmosphere may be classified into two types depending on their origin. Primary particles are directly emitted by a source while secondary particles are formed by the homogeneous condensation of gaseous precursors through a secondary process. This is known as new particle formation (NPF) and has been observed in many parts of the world in many different types of environments (Curtius, 2006; Kulmala et al., 2005, 2004; Zhang et al., 2011). NPF is a complicated process in which molecular clusters come together to form particles at a size of about $1.6 \mathrm{~nm}$ (Kulmala et al., 2004). Generally, it is favoured by clean air conditions in which the particle number concentration (PNC) in the atmosphere is low, resulting in a lower particle surface available for the condensation of gases. This leads to an increase in the supersaturation in the air, enhancing homogeneous condensation of the gaseous species (Kulmala et al., 2005; Wu et al., 2011) and therefore NPF is less frequent in polluted environments. However, if the gaseous precursor concentration is high enough, NPF may occur at even higher particle concentrations (Kulmala et al., 2005; Wu et al., 2011). Jayaratne et al. (2015) showed that in the relatively clean environment of Brisbane, Australia, NPF events do not occur when the ambient $\mathrm{PM}_{10}$ concentration exceeds about $20 \mu \mathrm{g} \mathrm{m}^{-3}$. However, NPF events have been commonly observed in more polluted environments like Beijing (Kulmama et al., 2016) and Shanghai (Xiao et al., 2015) in China. Kulmala et al. (2017) proposed that the survival efficiency of clusters to form particles is determined by two key parameters - condensation sink (CS) and cluster growth rate (GR). They defined a dimensionless survival parameter, $P$, equal 
to the ratio $\left(\mathrm{CS} / 10^{-4} \mathrm{~s}^{-1}\right) /\left(\mathrm{GR} \mathrm{nmh} \mathrm{h}^{-1}\right)$ and showed that $P$ needs to be smaller than about 50 for a notable NPF to take place. However, it was noted that NPF occurred frequently in megacities in China where the calculated $P$ values were much higher. They hypothesised that this discrepancy may be explained if the molecular clusters were being scavenged less effectively than expected based on their collision rates with pre-existing particles or if they grew much faster in size than our current understanding allows.

The study of the formation and characteristics of NPF events in Beijing is important because of its possible influence on severe haze episodes (Guo et al., 2014; Huang et al., 2014). Such haze events not only give rise to poor visibility but are responsible for sharp increases in respiratory problems amongst the large population that is exposed. In particular, Beijing experienced severe haze episodes during November and December 2015. Daily maximum $\mathrm{PM}_{2.5}$ values in the city exceeded $500 \mu \mathrm{g} \mathrm{m}^{-3}$ on no less than 6 days during the month of December, prompting two official air pollution red alerts to be issued (Xue et al., 2016). Close examination of the haze events demonstrates that they occur in cycles of a few days and generally coincide with winds blowing from the more polluted regions south of the city (Guo et al., 2014; Wu et al., 2007). Particulate matter concentrations are observed to drop significantly when the winds change to a northerly direction, bringing cleaner air into the city, which is when NPF events generally occur (Guo et al., 2014; Huang et al., 2014).

The earliest study of NPF using a TSI scanning mobility particle sizer (SMPS) in Beijing was carried out by Wehner et al. (2004). They observed NPF on 25 out of 45 days of measurement, and on each of these days the PNC exceeded $10^{5} \mathrm{~cm}^{-3}$. Subsequent studies using the SMPS were carried out by Wu et al. (2007), who showed that NPF events were observed on $50,20,35$, and $45 \%$ of days during the spring, summer, autumn, and winter seasons, respectively. Yue et al. (2010) investigated 12 NPF events and showed that sulfuric acid and ammonia accounted for about $45 \%$ of the growth rate, with the balance being due to organic species. Guo et al. (2014) conducted a detailed analysis over a 2-month period during the autumn of 2013 and showed that NPF events occurred in a clear periodic cycle of about 4-7 days coinciding with northerly winds bringing cleaner air into the city. The average $\mathrm{PM}_{2.5}$ values when the wind was from the north and when it was from the south were 35 and $114 \mu \mathrm{g} \mathrm{m}^{-3}$, respectively. The average $\mathrm{PM}_{2.5}$ (and PNC) values during and outside the NPF periods were less than $50 \mu \mathrm{g} \mathrm{m}^{-3}$ (greater than $2 \times 10^{5} \mathrm{~cm}^{-3}$ ) and several hundred microgrammes per cubic metre $\left(5 \times 10^{4} \mathrm{~cm}^{-3}\right)$, respectively. Pollution also originates from within the city - from motor vehicle emissions and industrial sources. In general, airborne gaseous pollutants in Beijing and other urban regions in China are mainly volatile organic compounds (VOCs) and oxides of nitrogen $\left(\mathrm{NO}_{x}\right)$ from local transportation and sulfur dioxide $\left(\mathrm{SO}_{2}\right)$ from regional industrial sources (Wang et al.,
2009; Yue et al., 2010). However, Guo et al. (2014) showed that the nucleation and growth processes occurred on a regional scale, over several hundred kilometres, with the effect of local sources such as motor vehicle emissions being insignificant. A good summary of the studies conducted since 2004 in Beijing may be found in Zhibin et al. (2013) and Kulmama et al. (2016).

All these previous studies in Beijing were carried out using the SMPS. The SMPS is a good tool to determine the PNC and size distribution down to a minimum particle size of about $3 \mathrm{~nm}$, although the efficiency of detection decreases below about $10 \mathrm{~nm}$. Thus, an event in which aerosols in the size range of 3-10 nm emitted on-site as primary particles or entrained from a distant location that continue to grow to larger sizes may be mistaken for particle formation at that monitoring site. The SMPS is also not able to identify the exact time period during which particle formation occurs. An instrument that can detect particles at smaller sizes is the neutral cluster and air ion spectrometer (NAIS) from Airel Ltd (Mirme et al., 2007). The NAIS is specifically designed to monitor NPF as it can detect particles down to their actual formation sizes (Manninen et al., 2016, 2009; Mirme et al., 2007). In this paper, we present the first results of using a NAIS in Beijing over the course of 3 months, 2 months with intense haze and very few NPF events, and the other month including several days with NPF events. We will investigate the characteristics of the NPF events and the conditions that gave rise to them. As the measurements included the sizes at which particles formed, the results provide more reliable information of such parameters as the starting times, growth rates, and formation rates of particles than has been possible in the past.

\section{Methods}

\subsection{Instrumentation}

The NAIS is an improved version of the air ion spectrometer (AIS), which was developed by Airel Ltd (Mirme et al., 2007). In both instruments, the sample air is split equally into each of two separate cylindrical spectrometer columns, one of each polarity. At the inlet to each column, a unipolar corona wire diffusion charger of the same polarity as the central electrode in the column brings the particles to an equilibrium charge distribution. They are then classified by a differential mobility analyser in which the outer electrodes consist of 21 insulated sections or rings, each with its own electrometer. The charged particles in the air flow are repelled by the central electrode, which has a tapered cross section, and collected by the rings. The electric field between the central electrode and the rings is fixed by the voltage on the inner electrode and the gap between the inner and outer electrodes so that only particles in a given mobility range may be collected by each ring. In this way, the instrument can sepa- 
rate particles into 21 mobility or size bins. A refinement in the NAIS over the AIS is that it uses controlled charging to measure the total PNC in each size range in addition to the concentration of charged particles. This is done by switching the voltage on the corona charger off during one part of the measurement cycle. Thus, the NAIS can measure both charged and neutral particles separately. The mobility range of the instrument is $3.16-0.001 \mathrm{~cm}^{2} \mathrm{~V}^{-1} \mathrm{~s}^{-1}$, which corresponds to a mobility diameter range of $0.8-42 \mathrm{~nm}$. However, Asmi et al. (2009) and Manninen et al. (2011, 2016) have pointed out that the lowest detection limit for the NAIS in the particle mode is about $2.0 \mathrm{~nm}$ owing to the presence of corona-generated ions; at sizes smaller than $2.0 \mathrm{~nm}$, the NAIS cannot reliably distinguish between charged and neutral particles. Therefore, Manninen et al. (2011) specified the lowest detection limit of the NAIS to be 1.6 and $1.7 \mathrm{~nm}$ for negative and positive ions, respectively, and $2.0 \mathrm{~nm}$ for neutral particles. Therefore, in this study, we will restrict our observations to the particle size range of $2.0-42 \mathrm{~nm}$. A good description of the detailed operation of the NAIS may be found in Manninen et al. (2016). In this study, we set the NAIS to a measurement cycle of $5 \mathrm{~min}$, consisting of $2 \mathrm{~min}$ each for charged and neutral particles, with an offset period of $1 \mathrm{~min}$. Thus, a PNC and charged particle concentration reading were obtained in real time once every $5 \mathrm{~min}$.

The larger-size PNC was monitored with an SMPS. The instrument was set to scan up and retrace times of 120 and $15 \mathrm{~s}$, respectively. The aerosol and sheath flow rates were 0.3 and $3.0 \mathrm{~L} \mathrm{~min}^{-1}$, respectively. Size distributions were determined in 107 bins in the size range from 14 to $673 \mathrm{~nm}$. A complete size distribution record was obtained every $5 \mathrm{~min}$. $\mathrm{PM}_{2.5}$ concentrations were monitored with a tapered element oscillating monitor (TEOM) and recorded as hourly average values.

\subsection{Study design}

The NAIS and SMPS were set up within a room on the roof of the Chinese Research in Atmospheric and Environmental Sciences (CRAES) building in Beiyuan, Beijing, on the 28 October 2015 and monitoring was conducted continuously until 31 January 2016. This comprised 96 days, including several episodes of very high pollution or haze days when the $\mathrm{PM}_{2.5}$ in Beijing exceeded 100-200 $\mu \mathrm{g} \mathrm{m}^{-3}$. Data were lost on 9 days owing to various problems such as the loss of power, software malfunction, and a blocked filter during a haze event. Air was sampled through a straight steel pipe of $4 \mathrm{~cm}$ diameter protruding vertically through the roof of the building. Meteorological parameters, including the wind speed, wind direction, air temperature, and relative humidity were monitored and recorded hourly over the course of the study period.

\subsection{Analysis}

\subsubsection{Identification of NPF events}

The NAIS provided spectrograms showing the neutral and charged particle number size distributions in real time with the concentrations shown in colour contours. The neutral and charged PNCs were also provided in real time at $5 \mathrm{~min}$ intervals. NPF events were identified using the method proposed by Zhang et al. (2004). We calculated the rate of change of PNC, $\mathrm{d} N / \mathrm{d} t$, in which $N$ is the number of particles in the size range of $2.0-10.0 \mathrm{~nm}$. Events with $N>10000 \mathrm{~cm}^{-3}$ for at least $1 \mathrm{~h}$ and $\mathrm{d} N / \mathrm{d} t>15000 \mathrm{~cm}^{-3} \mathrm{~h}^{-1}$ were classified as NPF events. These events generally exhibited a banana shape in the spectrograms. A day on which there was at least one NPF event as defined above was termed an "NPF day". A day where the criteria above were not fulfilled was classified as a "non-event" day. A "haze day" was defined as a day when the $24 \mathrm{~h}$ average $\mathrm{PM}_{2.5}$ concentration exceeded $75 \mu \mathrm{g} \mathrm{m}^{-3}$ the national air quality standard in China. A day on which there was neither a NPF event or haze was defined as a "normal day". NPF events are characterised by sharp increases in the intermediate size range. The starting time of an event was determined by using the time of sudden increase in PNC in the size range of $2.0-10.0 \mathrm{~nm}$.

\subsubsection{Condensation sink (CS) and coagulation sink (CoagS)}

The CS of particles is defined as (Dal Maso et al., 2002, 2005; Kulmala et al., 2012; Lehtinen et al., 2003; Salma et al., 2011)

$\mathrm{CS}=2 \pi D \sum_{i} \beta_{\mathrm{m}}\left(d_{\mathrm{p}, i}\right) d_{\mathrm{p}, i} N_{i}$,

in which $D$ is the diffusion coefficient of the condensing vapour and $\beta_{\mathrm{m}}$ is the transition correction factor for mass flux. The variables $d_{\mathrm{p}_{i}}$ and $N_{i}$ are the diameter and the number concentration, respectively, of particles in the size bin $i$. The unit of CS is per second.

It is now well established that sulfuric acid is the key precursor gas in nucleation, although low-vapour-pressure organics may contribute to the subsequent aerosol growth (Curtius, 2006). Sulfuric acid has a low vapour pressure, which is reduced further in the presence of water. When produced from $\mathrm{SO}_{2}$ in the gas phase, it is easily supersaturated and begins to condense. Moreover, most of the particles in the atmosphere are in the kinetic regime (smaller than $0.01 \mu \mathrm{m}$ ) (Seinfeld and Pandis, 2006a). In this regime, condensation is directly proportional to the RMS speed of the molecules. The RMS speed is inversely proportional to the square root of the molecular weight of the molecule. Thus, a sulfuric acid molecule, with a molecular weight of $98 \mathrm{~g} \mathrm{~mol}^{-1}$, has an RMS speed that is about $30 \%$ higher than a typical organic gas molecule with a molecular weight of about $200 \mathrm{~g} \mathrm{~mol}^{-1}$. 
Thus, condensation of sulfuric acid occurs much more readily than organic molecules. Studies in Beijing have confirmed that NPF is more likely to occur in a sulfur-rich environment than in one that is sulfur-poor (Yue et al., 2010; Guo et al., 2014; Wu et al., 2007). Wu et al. (2007) also assumed that sulfuric acid was the main condensable vapour in determining the particle formation rates during NPF events in Beijing.

Therefore, assuming that the main condensation vapour is sulfuric acid, we estimated the diffusion coefficient for condensing vapour using the expression

$$
\begin{aligned}
D & =5.0032 \times 10^{-6}+1.04 \times 10^{-8} T+1.64 \times 10^{-11} T^{2} \\
& -1.566 \times 10^{-14} T^{3},
\end{aligned}
$$

in which $D$ has the unit of square metres per second and the temperature $T$ is in Kelvin (Jeong, 2009).

The transition correction factor, $\beta_{\mathrm{m}}$, was calculated using the Fuchs-Sutugin expression (Fuchs and Sutugin, 1971):

$$
\beta_{\mathrm{m}}=\frac{K n+1}{1+\left(\frac{4}{3 \alpha}+0.337\right) K n+\left(\frac{4}{3 \alpha}\right) K n^{2}},
$$

in which

$$
K n=\frac{2 \lambda}{d_{\mathrm{p}}} \quad \text { and } \quad 0 \leq \alpha \leq 1 .
$$

Here, $K n$, the Knudsen number, describes the nature of the suspending vapour relative to the particle, $\lambda$ is the mean free path of a suspending vapour molecule, and $d_{\mathrm{p}}$ is the diameter of the particle (Seinfeld and Pandis, 2006b). The mass accommodation coefficient (sticking coefficient) $\alpha$ describes the probability of a vapour molecule sticking to the surface of a particle during vapour-particle interactions (Seinfeld and Pandis, 2006b). In this study, we assumed $\alpha=1$.

The relationship between the condensation sink and coagulation sink is given by Lehtinen et al. (2007) as

$\operatorname{CoagS}_{d_{\mathrm{p}}}=\operatorname{CS}\left(\frac{d_{\mathrm{p}}}{0.71}\right)^{m}$,

in which the exponent $m$ varies from -1.75 to -1.5 with a mean value -1.7 , and the value 0.71 is the diameter of a hydrated sulfuric acid molecule. The unit of CoagS is per second.

In order to calculate the CS, we used the PNC obtained from the SMPS in the 107 size bins in the range of 14$673 \mathrm{~nm}$ and from the NAIS in eight size bins in the range of 2-14 $\mathrm{nm}$. The mean temperature in Beijing during the period of observation was close to $0{ }^{\circ} \mathrm{C}$. The value of $D$ calculated using Eq. (2) at temperature $T=273 \mathrm{~K}$ was $0.087 \mathrm{~cm}^{2} \mathrm{~s}^{-1}$, which is in good agreement with the values given in the literature (Brus et al., 2016; Eisele and Hanson, 2000). The value used for the exponent $m$ was -1.7 (Dal Maso et al., 2008) and $\lambda=108 \mathrm{~nm}$ (Massman, 1998).

\subsubsection{Particle formation rate}

Particle formation or nucleation occurs from thermodynamically stable clusters in the size range of 1.0-2.0 nm (Kulmala et al., 2007). The formation rate may be estimated from the number of particles in the smallest size bin, usually $2-3 \mathrm{~nm}$ in the NAIS.

The formation rate of particles is defined as

$J_{d_{\mathrm{p}}}=\frac{\mathrm{d} N_{d_{\mathrm{p}}}}{\mathrm{d} t}+\operatorname{CoagS}_{d_{\mathrm{p}}} \cdot N_{d_{\mathrm{p}}}+\left(\frac{\mathrm{GR}}{\Delta d_{\mathrm{p}}}\right) N_{d_{\mathrm{p}}}$,

where $N_{d_{\mathrm{p}}}$ is the number concentration of particles in the size range $d_{\mathrm{p}}$ and $\left(d_{\mathrm{p}}+\Delta d_{\mathrm{p}}\right)$ (Kulmala et al., 2012). In this study, we used the values $d_{\mathrm{p}}=2 \mathrm{~nm}$ and $\Delta d_{\mathrm{p}}=1 \mathrm{~nm}$, corresponding to the size range $2-3 \mathrm{~nm}$. CoagS $S_{d_{\mathrm{p}}}$ represents the loss of the particles due to coagulation in the size range of $2-3 \mathrm{~nm}$, calculated from Eq. (4) with $d_{\mathrm{p}}=2 \mathrm{~nm}$, and GR is the growth rate of particles. The unit of formation rate is per cubic centimetre per second.

\subsubsection{Particle growth rate (GR)}

During a NPF event, the growth rate of particles was defined by Kulmala et al. (2012) as

$\mathrm{GR}=\frac{\mathrm{d} d_{\mathrm{p}}}{\mathrm{d} t}=\frac{d_{\mathrm{p}_{2}}-d_{\mathrm{p}_{1}}}{t_{2}-t_{1}}$,

in which $d_{\mathrm{p}_{2}}$ and $d_{\mathrm{p}_{1}}$ are the diameters of particles at times $t_{2}$ and $t_{1}$, respectively. This was calculated by the maximum concentration method as described in Kulmala et al. (2012) by examining the time of maximum PNC at each particle size during a NPF event. First, we exported the number concentrations of particles obtained from the NAIS in 14 bins in the size range of $2.0-42.0 \mathrm{~nm}$. Next, we selected the time of maximum concentrations during each NPF event for each particle size bin. Finally, we calculated the GR using the slope of the best-fitted line on the graph of median diameter of particle in each size bin vs. the time of maximum concentration. The unit of GR is nanometre per hour.

\section{Results and discussion}

\subsection{Distribution of NPF events}

During the entire period of measurement, the NAIS yielded 87 complete days of data, the remaining 9 days being affected by instrument faults, generally due to power fluctuations. November and December 2015 were particularly prone to high-pollution events in Beijing. The daily average $\mathrm{PM}_{2.5}$ concentration exceeded the recommended maximum of $50 \mu \mathrm{g} \mathrm{m}^{-3}$ in Beijing on 47 days during this 2-month period. The maximum daily average was $448 \mathrm{\mu g} \mathrm{m}^{-3}$ and this occurred on 1 December. Owing to the high condensation sink on polluted days, there were relatively few NPF days 


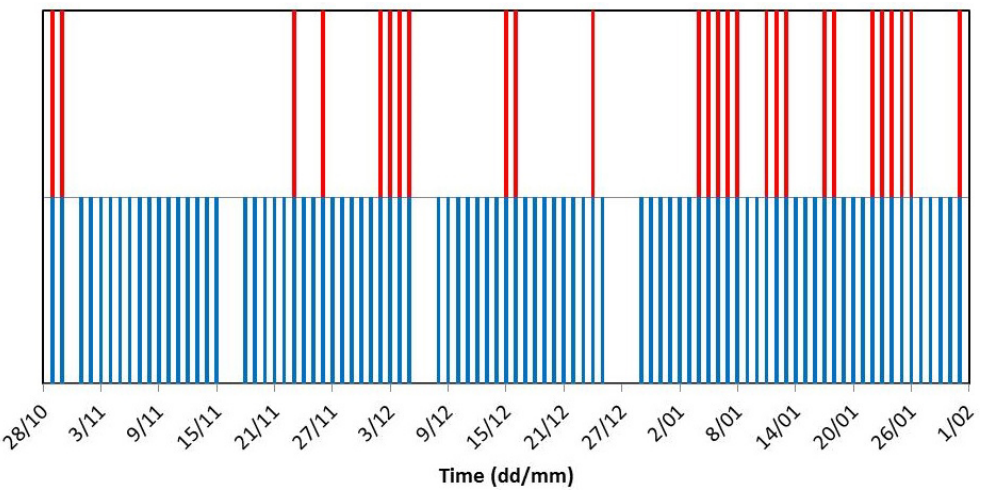

Figure 1. Summary of observational days (lower panel in blue) and days with NPF events (upper panel in red).

during these 2 months. There was a relative improvement in air quality after 4 January and this lasted until 31 January - the end of the monitoring period, during which time the daily average exceeded $100 \mu \mathrm{g} \mathrm{m}^{-3}$ on only 4 days. Enhanced $\mathrm{PM}_{2.5}$ concentrations $\left(>50 \mu \mathrm{g} \mathrm{m}^{-3}\right.$ ) were observed on 15 days in January. These days occurred in groups and we could identify five such distinct periods during January. No NPF events were observed during these 15 days; however, several NPF events were observed on the other days during the intervening periods. A summary of the observational days, together with the number of days for which data were available and NPF events were observed, is shown in Table 1. Column 3 shows the numbers of days for which complete $24 \mathrm{~h}$ data were obtained. We note that during the 56 such days between 27 October and 31 December, NPF events were observed on just 10 days, whereas during the 31 days in January 2016, NPF events took place on 16 days. The near equal division between NPF days and no-NPF days in January provided an ideal data set to compare the parameters and conditions on these two types of days. The difference between November and December and January had a clear dependence on the $\mathrm{PM}_{2.5}$ concentrations. Figure 1 gives a summary of the days on which NPF events were observed.

\subsection{Relationship between NPF events and $\mathbf{P M}_{2.5}$ concentration}

In Fig. 2, we take a closer look at the January data, together with the respective mean daily $\mathrm{PM}_{2.5}$ concentrations. It is apparent that there were five distinct groups of NPF days in January. These are labelled in Fig. 2b. In the NAIS spectrogram, shown in Fig. 2a, the 16 NPF events are clearly observed with the characteristic banana shapes compressed into near-vertical bands extending up from the smallest sizes. The five groups from left to right consist of 5, 3, 2, 5, and $1 \mathrm{NPF}$ events, respectively (Fig. 2a and b). These groups are separated by time periods when no NPF events were observed. The $\mathrm{PM}_{2.5}$ values are clearly lower on NPF days than on the other days, with mean daily values of 18 and $120 \mu \mathrm{g} \mathrm{m}^{-3}$, re-
Table 1. Summary of the observational days.

\begin{tabular}{lrrr}
\hline Month & $\begin{array}{r}\text { Total } \\
\text { days }\end{array}$ & $\begin{array}{r}\text { Data } \\
\text { available } \\
\text { days }\end{array}$ & $\begin{array}{r}\text { NPF days: } \\
\mathrm{d} N / \mathrm{d} t>15000 \\
\mathrm{~cm}^{-3} \mathrm{~h}^{-1}\end{array}$ \\
\hline October (28-31) & 4 & 2 & 2 \\
November (1-30) & 30 & 28 & 2 \\
December (1-31) & 31 & 26 & 6 \\
January (1-31) & 31 & 31 & 16 \\
\hline Total & 96 & 87 & 26 \\
\hline
\end{tabular}

spectively. A Student's $t$ test showed that the difference in mean daily $\mathrm{PM}_{2.5}$ values between NPF days and the other days was statistically significant at the confidence level of $95 \%$. The corresponding difference was even more significant when considering the entire monitoring period in which the mean daily values of $\mathrm{PM}_{2.5}$ on NPF days and the other days were 21 and $143 \mu \mathrm{g} \mathrm{m}^{-3}$, respectively. Figure $2 \mathrm{c}$ shows the corresponding mean daily PNC. While the PNC within each group showed a greater fluctuation than the $\mathrm{PM}_{2.5}$, the PNC on NPF days was significantly higher than on non-NPF days. Therefore, although the PM is higher on haze days than on NPF days, the $t$ tests again showed that the PNC was significantly lower on haze days than on NPF days. This is explicable in terms of the particle size. Particles are significantly larger on haze days than on clean days when NPF events are likely to occur.

In Fig. 3, we plot the daily mean PNC against the daily mean $\mathrm{PM}_{2.5}$ for the 31 days in January. The days with NPF and the days with no NPF events clearly fall into two distinct groups according to the daily mean $\mathrm{PM}_{2.5}$ values. Preexisting particles entering the region with the winds from the south also increase the condensation sink, further reducing the likelihood of NPF.

No NPF events were observed on a day when the mean $\mathrm{PM}_{2.5}$ value exceeded $43 \mu \mathrm{g} \mathrm{m}^{-3}$. There is some minor overlap in the PNC values for the two types of days but this is 

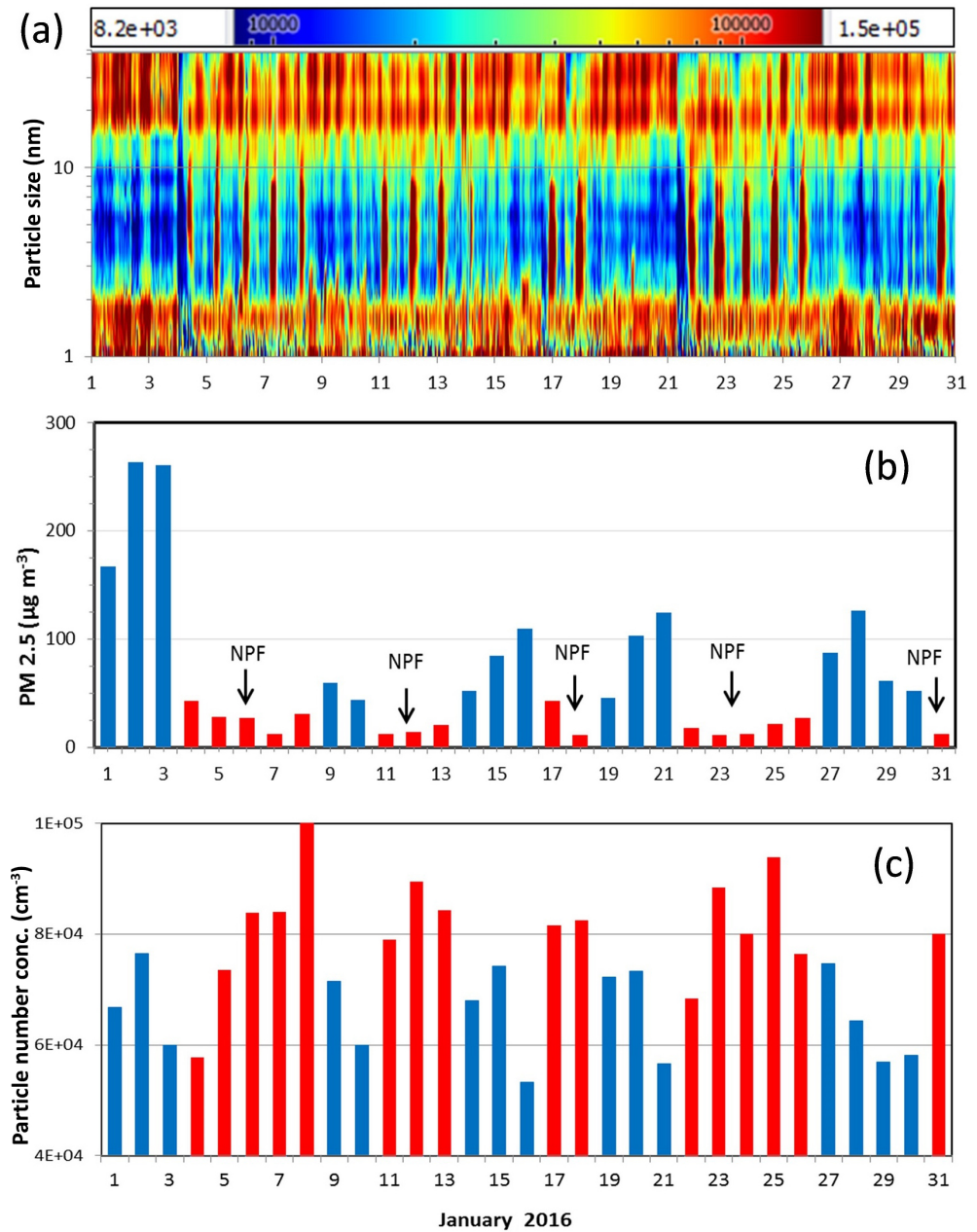

Figure 2. Daily values for January 2016: (a) NAIS spectrogram of PNC on a particle size-time diagram, (b) mean $\mathrm{PM}_{2.5}$ concentration from the TEOM, and (c) mean PNC in the size range of 2-42 nm from the NAIS. In (a), the unit of PNC is per cubic centimetre. Data below $2.0 \mathrm{~nm}$ should be treated with caution due to instrumentation limitations as described in the text. In (c), the red and blue bars represent the NPF days and other days, respectively.

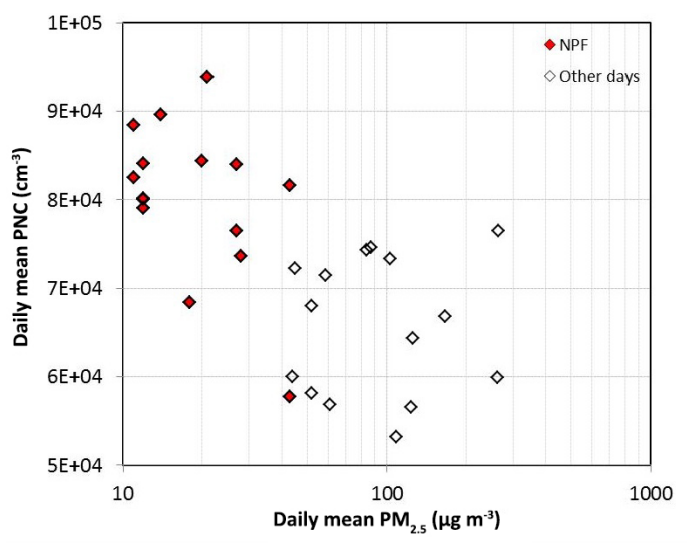

Figure 3. Daily mean PNC vs. $\mathrm{PM}_{2.5}$ for NPF days (filled markers) and other days (open markers) during January 2016. primarily because they are daily averages. When we consider the average PNC values during the NPF events alone, a $t$ test showed that they are significantly higher than on other days and at other times. However, we do see that, on haze days, the daily average PNC does not exceed $8.5 \times 10^{4} \mathrm{~cm}^{-3}$.

\subsection{Relationship between NPF events and wind direction}

Previous studies have shown that the wind direction played an important role in determining the $\mathrm{PM}_{2.5}$ concentration in Beijing (Guo et al., 2014). Again, we look at the month of January, as it provided an almost equal number of NPF days and other days and was, therefore, ideal to compare the wind direction on the two types of days. Figure 4 shows the wind direction roses for both NPF days and other days during January. The frequencies are given as percentages of time when the wind was from a given direction. There is a clear dif- 


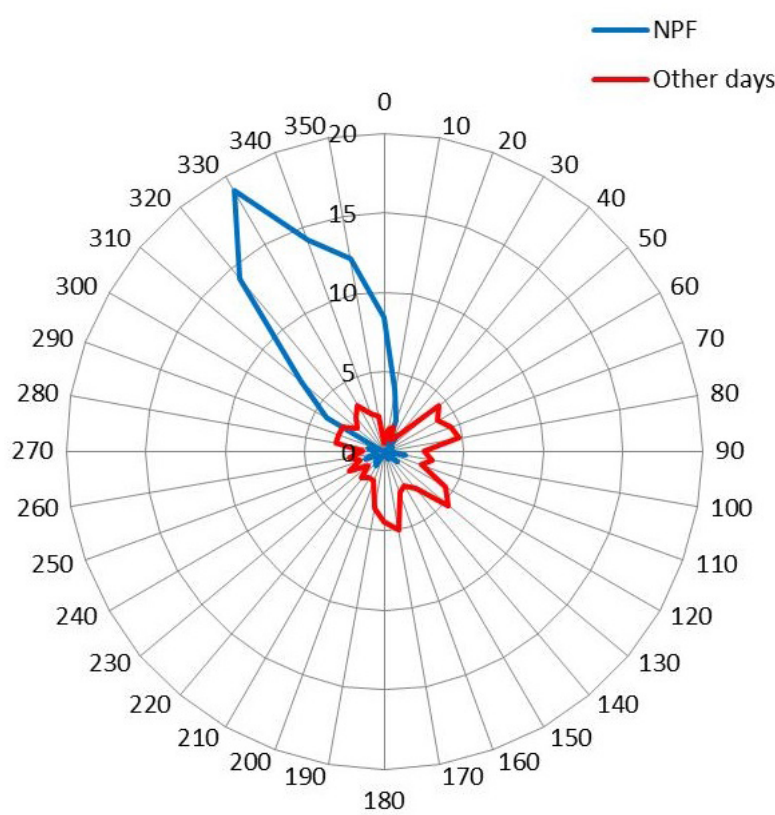

Figure 4. The wind direction rose for NPF days and other days during January. The radial scale indicates percentages of time.

ference between the two sets of days, with a strong correlation between the NPF days and the wind direction. NPF events clearly occurred on days when the wind direction was predominantly from the NW, while it was more equally distributed with a greater likelihood of arriving from the $\mathrm{S}$ and E during the haze days when there were no NPF events. The frequencies in the sector between $\mathrm{NW}\left(315^{\circ}\right)$ and $\mathrm{N}\left(0^{\circ}\right)$ on NPF days and other days were 68 and $11 \%$, respectively. Air from the north of Beijing is usually cleaner than that from the more industrialised south of the city (Guo et al., 2014). Clean periods are characterised by decreased condensation sinks that promote NPF. Winds from the south bring a copious supply of freshly available gaseous precursors that should give rise to particle formation. However, the absence of NPF events during these times suggests that the wind also carries a large supply of particles that reduce the gaseous supersaturations required for particle formation. Thus, the observed haze events are unlikely to be caused by in situ new particle formation and more likely to be due to particles carried by the wind into the city or being prevented from escaping due to temperature inversions in the atmosphere.

\subsection{Charged particles}

Next, we look at the behaviour of charged particles, with particular attention paid to NPF events and haze events. In order to compare and contrast the characteristics of these particles, we selected a period of 4 days, comprising 2 haze days that were immediately followed by 2 NPF days. Figure 5 shows the time series of the concentration of total and charged par-
Table 2. Mean and peak values of neutral and charged particle concentrations during the various types of days and events. The associated uncertainties in the values are up to $20 \%$. The percentage column shows the percentage of particles that were charged.

\begin{tabular}{lrcr}
\hline & \multicolumn{3}{c}{ Particles $\left(\mathrm{cm}^{-3}\right)$} \\
\cline { 2 - 4 } & $\begin{array}{c}\text { Neutral } \\
\left(\times 10^{4}\right)\end{array}$ & $\begin{array}{c}\text { Charged } \\
\left(\times 10^{4}\right)\end{array}$ & $\%$ \\
\hline Normal days (mean) & 5.6 & 0.9 & 14.5 \\
NPF days (mean) & 7.6 & 0.8 & 10.1 \\
NPF events (peak) & 22.5 & 1.3 & 5.6 \\
Haze days (mean) & 4.8 & 1.9 & 28.6 \\
Haze events (peak) & 11.7 & 2.9 & 20.1 \\
\hline
\end{tabular}

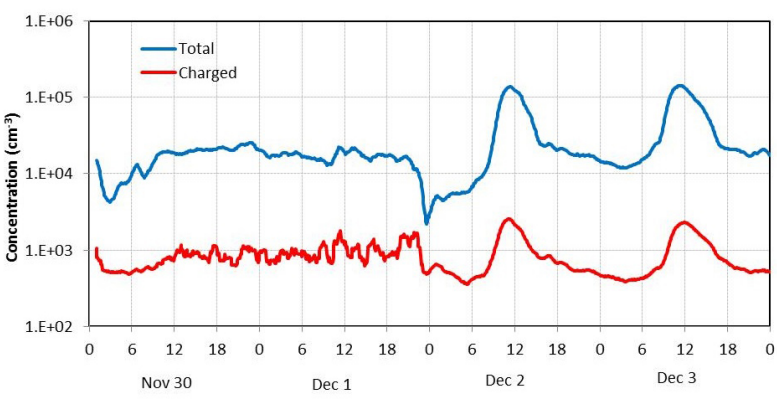

Figure 5. Time series of total and charged particles during the period from 30 November to 3 December as measured by the NAIS. The 30 November and 1 December were haze days, while two NPF events occurred on 2 and 3 December.

ticles observed over this 4-day period from 30 November to 3 December. The upper curve represents the total PNC while the lower curve gives the charged PNC. The difference between the two curves gives the neutral PNC. The conditions during the two types of events could be compared during this period as intense haze was observed on the first 2 days (30 November and 1 December) while, following a change of wind direction near midnight on the 1 December, two strong NPF events took place on the next 2 days ( 2 and 3 December).

A summary of the neutral and charged PNCs during the various stages over the entire period of observation are presented in Table 2. Also shown are the percentage numbers of all particles that were found to be charged. NPF events and NPF days are defined in Sect. 2.3.1. A haze day was defined as a day when the $24 \mathrm{~h}$ average $\mathrm{PM}_{2.5}$ concentration exceeded $75 \mu \mathrm{g} \mathrm{m}^{-3}$ - the national air quality standard in China. A day that met neither of these criteria was defined as a normal day. Thus, by our ad hoc definition, a normal day had a daily average $\mathrm{PM}_{2.5}$ concentration in the range of $43-75 \mu \mathrm{g} \mathrm{m}^{-3}$ since no NPF events were observed on days when the average $\mathrm{PM}_{2.5}$ concentration was greater than $43 \mu \mathrm{g} \mathrm{m}^{-3}$. The duration of the various events affected the daily values while the conditions during the events affected their peak number 
concentrations. The values shown are the means of the average $\mathrm{PM}_{2.5}$ concentrations over all the $24 \mathrm{~h}$ days. The daily mean values varied from day to day, especially on days with NPF events or haze events, mainly due to the different durations of these events. We estimated the SD about these mean values to be $20 \%$.

On a normal day, around $15 \%$ of the particles larger than $2 \mathrm{~nm}$ are charged. The fraction that is charged decreases significantly during a NPF event. This is consistent with our observations in Brisbane (Jayaratne et al., 2016) and may be attributed to the rapid increase in particle number and the associated coagulation. Conversely, during a haze event, the percentage of particles charged increases to a value between 20 and $30 \%$. These observations are consistent with the PNC and particle sizes and the equilibrium distribution of charge on particles. NPF events are characterised by large numbers of small particles while the SMPS and TEOM show that haze events comprise much larger particles. The amount of charge that a particle can hold and the number of particles that are charged in equilibrium both increase with particle size; thus, it is not unexpected to find that a larger percentage of particles is charged during the haze events.

\subsection{Particle formation times}

All except one of the $26 \mathrm{NPF}$ events during the period of observation began between 07:30 and 10:00 LT. The mean time was 08:45 LT. This result is in agreement with $\mathrm{Wu}$ et al. (2007), who, using a SMPS, reported that NPF events during clean air periods in November, December, and January generally started between 07:00 and 10:00 LT. Figure 6 shows the temporal distribution of the start times of the NPF events, classified into $30 \mathrm{~min}$ bins. The most likely time for a NPF event to begin was between 08:00 and 08:30 LT. This time coincides with the morning rush hour traffic when the production rate of gaseous precursors is generally at a maximum. Sunrise in Beijing in December-January is at about 07:30 LT.

Figure 7 shows the NAIS spectrogram of the strong NPF event that occurred on 29 October 2015. The spectrogram shows a clear banana profile, which levels off at about $20 \mathrm{~nm}$. The PNC in this event was relatively high, exceeding $1.6 \times 10^{5} \mathrm{~cm}^{-3}$ near 11:00 LT. The $\mathrm{PM}_{2.5}$ concentration remained between 12 and $16 \mu \mathrm{g} \mathrm{m}^{-3}$ right through this event. The markers shown on this figure are the median sizes of particles at each time. It can be observed in the spectrogram that particle formation began at around 09:00 LT. However, previous studies in Beijing have not been able to measure particles smaller than $3 \mathrm{~nm}$. In Fig. 7, if we truncate the lower particle size margin to $3 \mathrm{~nm}$, the starting time of the NPF event appears later than it actually is, approximately at 09:30 LT. In other NPF spectrograms, we see this difference being as much as 1.0 to $1.5 \mathrm{~h}$ depending on the initial growth rate. Thus, we conclude that the starting times that we have derived (Fig. 6) are more accurate than those obtained in the

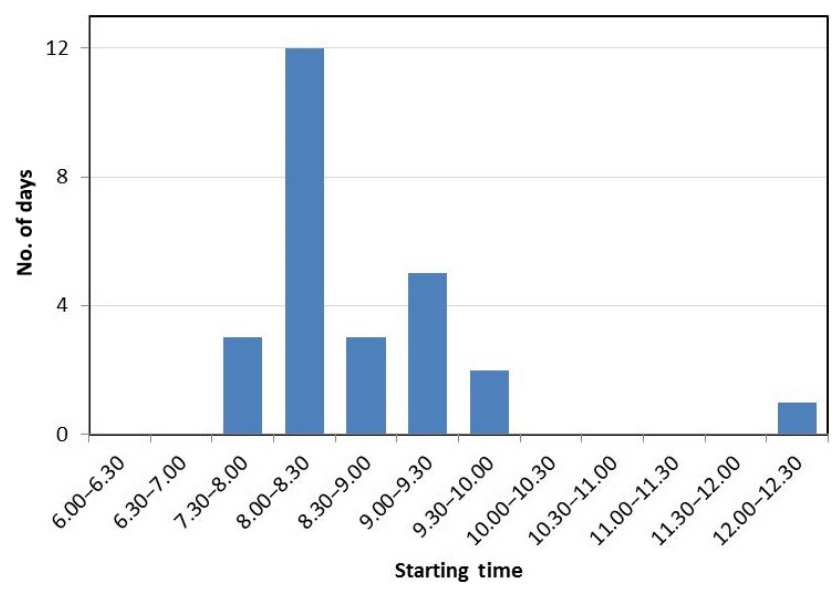

Figure 6. Distribution of the start times of the NPF events, classified into $30 \mathrm{~min}$ bins.

past. This will also affect the estimated GRs of particles during NPF events as we shall show in the next section.

\subsection{Condensation sink}

The CSs were calculated during NPF events, assuming the growth to be due to sulfuric acid and using the SMPS and NAIS data and the equations given in the methods section. The mean value of the CS was $4.2 \times 10^{-3} \mathrm{~s}^{-1}$. This value is somewhat smaller than that reported by Wu et al. (2007) $\left(1.4 \times 10^{-2} \mathrm{~s}^{-1}\right)$ and $\mathrm{Wu}$ et al. $(2011)\left(1 \times 10^{-2} \mathrm{~s}^{-1}\right)$ but within the range of $0-5 \times 10^{-2} \mathrm{~s}^{-1}$ reported in all NPF events between 2004 and 2008 in Beijing by Zhibin et al. (2013). The value of the CS during NPF events $\left(0.004 \mathrm{~s}^{-1}\right)$ was not significantly different to the corresponding average values during other times on NPF days and on normal days with no NPF $\left(0.006 \mathrm{~s}^{-1}\right)$. However, the mean CS on haze days $\left(0.060 \mathrm{~s}^{-1}\right)$ was significantly higher than both these values.

\subsection{Particle formation rate}

Using our value of the CS, we calculated the mean value of the coagulation sink using Eq. (4) for $2 \mathrm{~nm}$ particles during a NPF event to be $7.2 \times 10^{-4} \mathrm{~s}^{-1}$. Previous studies in Beijing have not been able to determine this value at $2 \mathrm{~nm}$. The value reported for $3 \mathrm{~nm}$ particles for NPF events in Beijing by Wu et al. (2011) was $9.9 \times 10^{-4} \mathrm{~s}^{-1}$, which is close to our value at $2 \mathrm{~nm}$. Using our value of the coagulation sink in Eq. (5), we calculated the formation rate of particles in the smallest particle size bin $2-3 \mathrm{~nm}$. At these times, the rate of increase of particles in this size bin ranged from about $5.0 \times 10^{3}$ to $1.5 \times 10^{4} \mathrm{~cm}^{-3} \mathrm{~h}^{-1}$. The resulting formation rates varied between 12 and $38 \mathrm{~cm}^{-3} \mathrm{~s}^{-1}$, with a mean of $26 \mathrm{~cm}^{-3} \mathrm{~s}^{-1}$. Previous estimates in Beijing did not have the benefit of the PNC information in the 2-3 nm size bin. Wu et al. (2007) calculated the formation rate in the wider size bin of 3-10 nm and arrived at a value in the range of $3.3-81.4 \mathrm{~cm}^{-3} \mathrm{~s}^{-1}$ with 


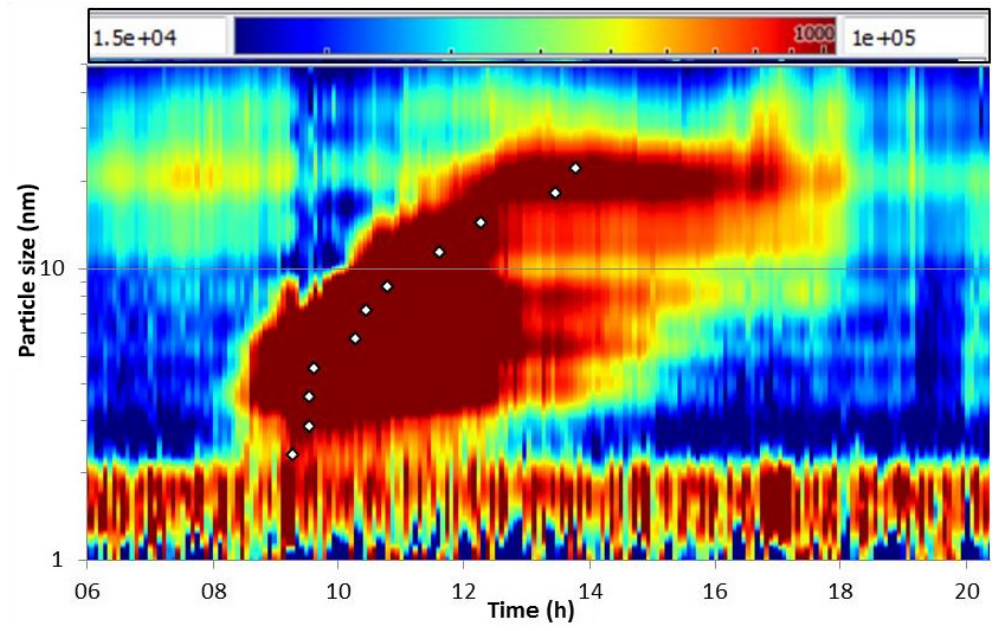

Figure 7. NAIS spectrogram of the NPF event that occurred on 29 October. The clear banana shape indicates strong particle growth. The markers show the median particle size at each time. The unit of PNC is per cubic centimetre. Data below $2.0 \mathrm{~nm}$ should be treated with caution due to instrumentation limitations as described in the text.

a mean of $22.3 \mathrm{~cm}^{-3} \mathrm{~s}^{-1}$. Yue et al. (2010) studied $12 \mathrm{NPF}$ events in Beijing and derived a formation rate in the range of $2-13 \mathrm{~cm}^{-3} \mathrm{~s}^{-1}$ and showed that the formation rate was directly proportional to the sulfuric acid concentration. They did not specify the size range used in this calculation but the smallest detectable particle size of the instrument used was $3 \mathrm{~nm}$. These values may be compared with those found by $\mathrm{Yu}$ et al. (2016) in the urban atmosphere of Nanjing, China. They studied eight NPF events using a nano-condensation nucleus counter system capable of measuring particle size distributions down to $1.4 \mathrm{~nm}$ and estimated initial and peak particle formation rates of $2.1 \times 10^{2}$ and $2.5 \times 10^{3} \mathrm{~cm}^{-3} \mathrm{~s}^{-1}$, respectively. The formation rates showed good linear correlation with a sulfuric acid proxy.

\subsection{Particle growth rate}

In the NPF event shown in Fig. 7, the particle GR in the size range of 2-10 nm during the entire event (between 09:00 and 11:00 LT) estimated from Eq. (6) was $4.8 \mathrm{~nm} \mathrm{~h}^{-1}$. Although the PNC reached very high values, the particles did not grow much larger than about $30 \mathrm{~nm}$, suggesting that the high CS was restricting the precursor gas concentration in the atmosphere. The GR of all the NPF events observed ranged from 0.5 to $9.0 \mathrm{nmh}^{-1}$ with a mean value of $3.5 \mathrm{nmh}^{-1}$. Previous estimates of the GR during NPF using the SMPS have yielded mean values of $1.0 \mathrm{~nm} \mathrm{~h}^{-1}$ (Wehner et al., 2004) and $1.8 \mathrm{~nm} \mathrm{~h}^{-1}$ (Wu et al., 2007). Zhibin et al. (2013) determined the GRs of a number of NPF events in Beijing over a 4-year period and reported a range of 0.1 to $10 \mathrm{~nm} \mathrm{~h}^{-1}$ with a mean of $3.0 \mathrm{nmh}^{-1}$, which is in close agreement with our value. In contrast, Yu et al. (2016) reported an exceptionally high local maximum GR of $25 \mathrm{nmh}^{-1}$ in Nanjing, China. Our values of $\mathrm{CS}$ and GR give a cluster survival parameter $P=12$ (Kul-
Table 3. Summary of mean and range of parameters calculated for the NPF events observed.

\begin{tabular}{lll}
\hline Parameter & Mean & Range \\
\hline Starting time of NPF & $08: 45 \mathrm{LT}$ & $07: 30-12: 30 \mathrm{LT}$ \\
Condensation sink $\left(\mathrm{s}^{-1}\right)$ & $4.2 \times 10^{-3}$ & $(2.3-5.7) \times 10^{-3}$ \\
Coagulation sink $\left(\mathrm{s}^{-1}\right)$ & $7.2 \times 10^{-4}$ & $(3.9-9.7) \times 10^{-4}$ \\
Formation rate $\left(J_{2}\right)\left(\mathrm{cm}^{-3} \mathrm{~s}^{-1}\right)$ & 26 & $12-38$ \\
Growth rate $\left(\mathrm{nm} \mathrm{h}^{-1}\right)$ & 3.5 & $0.5-9.0$ \\
\hline
\end{tabular}

mala et al., 2017). This value is significantly lower than the maximum value of 50 that was specified as a condition for NPF.

\section{Summary and conclusions}

We monitored charged and neutral PNCs over a continuous 3-month period for the first time in Beijing. The results showed 26 NPF events. No NPF events were observed when the daily mean $\mathrm{PM}_{2.5}$ concentration exceeded $43 \mu \mathrm{g} \mathrm{m}^{-3}$.

A summary of the main parameters determined is shown in Table 3.

This is the first study of NPF in the particle size range below $3 \mathrm{~nm}$ in Beijing. This enables the derivation of more relevant and accurate estimates of parameters, such as the times of formation and growth and formation rates, than has been possible before.

The results show the following features of NPF events in Beijing: 
- NPF events occur during clean air episodes when the wind direction is from the north of the city.

- We have provided the first temporal distribution chart of NPF events in Beijing, showing that all but one of the 26 events began between 07:30 and 10:00 LT.

- The main characteristics of the particles in the NPF events are presented in Table 3.

- The percentage of particles that are charged was normally about $15 \%$. This fraction increased to $20-30 \%$ during haze events and decreased to below $10 \%$ during NPF events.

Data availability. All data used in this paper are available upon request from Lidia Morawska (1.morawska@qut.edu.au).

Competing interests. The authors declare that they have no conflict of interest.

Acknowledgements. This project was supported by the AustraliaChina Centre for Air Quality Science and Management, the National Natural Science Foundation of China (grant nos. 41375132 and 91544226), and the Special Funds for Research on Public Welfares of the Ministry of Environmental Protection of China (201409003).

Edited by: Delphine Farmer

Reviewed by: two anonymous referees

\section{References}

Asmi, E., Sipilä, M., Manninen, H. E., Vanhanen, J., Lehtipalo, K., Gagné, S., Neitola, K., Mirme, A., Mirme, S., Tamm, E., Uin, J., Komsaare, K., Attoui, M., and Kulmala, M.: Results of the first air ion spectrometer calibration and intercomparison workshop, Atmos. Chem. Phys., 9, 141-154, https://doi.org/10.5194/acp-9141-2009, 2009.

Brus, D., Skrabalova, L., Herrmann, E., Olenius, T., Travnickova, T., and Merikanto, J.: Temperature-dependent diffusion coefficient of $\mathrm{H}_{2} \mathrm{SO}_{4}$ in air: laboratory measurements using laminar flow technique, Atmos. Chem. Phys. Discuss., https://doi.org/10.5194/acp-2016-398, 2016.

Curtius, J.: Nucleation of atmospheric aerosol particles, C. R. Phys., 7, 1027-1045, 2006.

Dal Maso, M., Kulmala, M., Lehtinen, K., Mäkelä, J., Aalto, P., and O'Dowd, C.: Condensation and coagulation sinks and formation of nucleation mode particles in coastal and boreal forest boundary layers, J. Geophys. Res.-Atmos., 107, 8097, https://doi.org/10.1029/2001JD001053, 2002.

Dal Maso, M., Kulmala, M., Riipinen, I., Wagner, R., Hussein, T., Aalto, P. P., and Lehtinen, K. E.: Formation and growth of fresh atmospheric aerosols: eight years of aerosol size distribution data from SMEAR II, Hyytiala, Finland, Boreal Environ. Res., 10, 323-336, 2005.

Dal Maso, M., Hyvärinen, A., Komppula, M., Tunved, P., KERMINEN, V., Lihavainen, H., Viisanen, Y., HANSSON, H. C., and Kulmala, M.: Annual and interannual variation in boreal forest aerosol particle number and volume concentration and their connection to particle formation, Tellus B, 60, 495-508, 2008.

Eisele, F. and Hanson, D.: First measurement of prenucleation molecular clusters, J. Phys. Chem. A, 104, 830-836, 2000.

Guo, S., Hu, M., Zamora, M. L., Peng, J., Shang, D., Zheng, J., Du, Z., Wu, Z., Shao, M., and Zeng, L.: Elucidating severe urban haze formation in China, P. Natl. Acad. Sci. USA, 111, 1737317378, 2014.

Huang, R.-J., Zhang, Y., Bozzetti, C., Ho, K.-F., Cao, J.-J., Han, Y., Daellenbach, K. R., Slowik, J. G., Platt, S. M., and Canonaco, F.: High secondary aerosol contribution to particulate pollution during haze events in China, Nature, 514, 218-222, 2014.

Jayaratne, E. R., Clifford, S., and Morawska, L.: Atmospheric visibility and $\mathrm{PM}_{10}$ as indicators of new particle formation in an urban environment, Environ. Sci. Technol., 49, 12751-12757, 2015.

Jayaratne, E. R., Ling, X., and Morawska, L.: Charging state of aerosols during particle formation events in an urban environment and its implications for ion-induced nucleation, Aerosol Air Qual. Res., 16, 348-360, 2016.

Jeong, K.: Condensation of water vapor and sulfuric acid in boiler flue gas, ProQuest, Lehigh University, ProQuest Dissertations Publishing, 2009.

Kulmala, M., Vehkamaki, H., Petaja, T., Dal Maso, M., Lauri, A., Kerminen, V., Birmilli, W., and McMurry, P.: Formation and growth rates of ultrafine atmospheric particles: a review of observations, J. Aerosol Sci., 35, 143-176, 2004.

Kulmala, M., Petäjä, T., Mönkkönen, P., Koponen, I. K., Dal Maso, M., Aalto, P. P., Lehtinen, K. E. J., and Kerminen, V.-M.: On the growth of nucleation mode particles: source rates of condensable vapor in polluted and clean environments, Atmos. Chem. Phys., 5, 409-416, https://doi.org/10.5194/acp-5-409-2005, 2005.

Kulmala, M., Riipinen, I., Sipilä, M., Manninen, H. E., Petäjä, T., Junninen, H., Dal Maso, M., Mordas, G., Mirme, A., and Vana, M.: Toward direct measurement of atmospheric nucleation, Science, 318, 89-92, 2007.

Kulmala, M., Petäjä, T., Nieminen, T., Sipilä, M., Manninen, H. E., Lehtipalo, K., Dal Maso, M., Aalto, P. P., Junninen, H., and Paasonen, P.: Measurement of the nucleation of atmospheric aerosol particles, Nat. Protoc., 7, 1651-1667, 2012.

Kulmala, M., Kerminen, V.-M., Petäjä, T., Aijun, D., and Wang, L.: Atmospheric gas-to-particle conversion: why NPF events are observed in megacities?, Faraday Discuss., https://doi.org/10.1039/C6FD00257A, 2017.

Kulmama, M., Petäjä, T., Kerminen, V.-M., Kujansuu, J., Ruuskanen, T., Ding, A., Nie, W., Hu, M., Wang, Z., and Wu, Z.: On secondary new particle formation in China, Front. Env. Sci. Eng., 10, 1-10, 2016.

Lehtinen, K. E., Korhonen, H., Maso, M., and Kulmala, M.: On the concept of condensation sink diameter, Boreal Environ. Res., 8, 405-412, 2003.

Lehtinen, K. E., Dal Maso, M., Kulmala, M., and Kerminen, V.M.: Estimating nucleation rates from apparent particle forma- 
tion rates and vice versa: revised formulation of the KerminenKulmala equation, J. Aerosol Sci., 38, 988-994, 2007.

Manninen, H. E., Petaja, T., Asmi, E., Ripinen, I., Nieminen, T., Mikkila, J., Horrak, U., Mirme, A., Mirme, S., Laakso, L., Kerminen, V., and Kulmala, M.: Long-term field measurements of charged and neutral clusters using Neutral cluster and Air Ion Spectrometer (NAIS), Boreal Environ. Res., 14, 591-605, 2009.

Manninen, H., Franchin, A., Schobesberger, S., Hirsikko, A., Hakala, J., Skromulis, A., Kangasluoma, J., Ehn, M., Junninen, H., and Mirme, A.: Characterisation of corona-generated ions used in a Neutral cluster and Air Ion Spectrometer (NAIS), Atmos. Meas. Tech., 4, 2767-2776, https://doi.org/10.5194/amt4-2767-2011, 2011.

Manninen, H. E., Mirme, S., Mirme, A., Petäjä, T., and Kulmala, M.: How to reliably detect molecular clusters and nucleation mode particles with Neutral cluster and Air Ion Spectrometer (NAIS), Atmos. Meas. Tech., 9, 3577-3605, https://doi.org/10.5194/amt-9-3577-2016, 2016.

Massman, W.: A review of the molecular diffusivities of $\mathrm{H}_{2} \mathrm{O}, \mathrm{CO}_{2}$, $\mathrm{CH}_{4}, \mathrm{CO}, \mathrm{O}_{3}, \mathrm{SO}_{2}, \mathrm{NH}_{3}, \mathrm{~N}_{2} \mathrm{O}, \mathrm{NO}$, and $\mathrm{NO}_{2}$ in air, $\mathrm{O}_{2}$ and $\mathrm{N}_{2}$ near STP, Atmos. Environ., 32, 1111-1127, 1998.

Mirme, A., Tamm, E., Mordas, G., Vana, M., Uin, J., Mirme, S., Bernotas, T., Laakso, L., Hirsikko, A., and Kulmala, M.: A widerange multi-channel Air Ion Spectrometer, Boreal Environ. Res., 12, 247-264, 2007.

Salma, I., Borsós, T., Weidinger, T., Aalto, P., Hussein, T., Dal Maso, M., and Kulmala, M.: Production, growth and properties of ultrafine atmospheric aerosol particles in an urban environment, Atmos. Chem. Phys., 11, 1339-1353, https://doi.org/10.5194/acp-11-1339-2011, 2011.

Seinfeld, J. H. and Pandis, S. N.: Atmospheric chemistry physics, Wiley, Hoboken, NJ, 2006b.

Wang, M., Zhu, T., Zheng, J., Zhang, R. Y., Zhang, S. Q., Xie, X. X., Han, Y. Q., and Li, Y.: Use of a mobile laboratory to evaluate changes in on-road air pollutants during the Beijing 2008 Summer Olympics, Atmos. Chem. Phys., 9, 8247-8263, https://doi.org/10.5194/acp-9-8247-2009, 2009.

Wehner, B., Wiedensohler, A., Tuch, T., Wu, Z., Hu, M., Slanina, J., and Kiang, C.: Variability of the aerosol number size distribution in Beijing, China: new particle formation, dust storms, and high continental background, Geophys. Res. Lett., 31, L22108, https://doi.org/10.1029/2004GL021596, 2004.
Wu, Z., Hu, M., Liu, S., Wehner, B., Bauer, S., Wiedensohler, A., Petäjä, T., Dal Maso, M., and Kulmala, M.: New particle formation in Beijing, China: statistical analysis of a 1 year data set, J. Geophys. Res.-Atmos., 112, D09209, https://doi.org/10.1029/2006JD007406, 2007.

Wu, Z., Hu, M., Yue, D., Wehner, B., and Wiedensohler, A.: Evolution of particle number size distribution in an urban atmosphere during episodes of heavy pollution and new particle formation, Sci. China Earth Sci., 54, 1772, 2011.

Xiao, S., Wang, M. Y., Yao, L., Kulmala, M., Zhou, B., Yang, X., Chen, J. M., Wang, D. F., Fu, Q. Y., Worsnop, D. R., and Wang, L.: Strong atmospheric new particle formation in winter in urban Shanghai, China, Atmos. Chem. Phys., 15, 1769-1781, https://doi.org/10.5194/acp-15-1769-2015, 2015.

Xue, Y. F., Zhou, Z., Nie, T., Pan, T., Qi, J., Nie, L., Wang, Z. S., Li, Y. T., Li, X. F., and Tian, H. Z.: Exploring the Severe Haze in Beijing During December, 2015: Pollution Process and Emissions Variation, Huan Jing Ke Xue, 37, 1593-1601, 2016.

Yu, H., Zhou, L., Dai, L., Shen, W., Dai, W., Zheng, J., Ma, Y., and Chen, M.: Nucleation and growth of sub-3 nm particles in the polluted urban atmosphere of a megacity in China, Atmos. Chem. Phys., 16, 2641-2657, https://doi.org/10.5194/acp16-2641-2016, 2016.

Yue, D. L., Hu, M., Zhang, R. Y., Wang, Z. B., Zheng, J., Wu, Z. J., Wiedensohler, A., He, L. Y., Huang, X. F., and Zhu, T.: The roles of sulfuric acid in new particle formation and growth in the mega-city of Beijing, Atmos. Chem. Phys., 10, 4953-4960, https://doi.org/10.5194/acp-10-4953-2010, 2010.

Zhang, Q., Stanier, C., Canagaratna, M., Jayne, J., Worsnop, D., Pandis, S., and Jiminez, J.: Insights into the chemistry of new particle formation and growth events in pittsburgh based on aerosol mass spectrometry, Environ. Sci. Technol., 38, 4797-4809, 2004.

Zhang, R., Khalizov, A., Wang, L., Hu, M., and Xu, W.: Nucleation and growth of nanoparticles in the atmosphere, Chem. Rev., 112, 1957-2011, 2011.

Zhibin, W., Min, H., Zhijun, W., and Dingli, Y.: Reasearch on the Formation Mechanisms of New Particles in the Atmosphere, Acta Chim. Sinica, 71, 519-527, 2013. 